\title{
Virtual Exhibitions: What do we win and what do we lose?
}

\author{
Katrin Wolf \& Jens Reinhardt \\ Hamburg University of Applied Sciences \\ Hamburg, Germany \\ firstname.name@haw-hamburg.de
}

\author{
Markus Funk \\ Technical University Darmstadt \\ Darmstadt, Germany \\ funk@tk.tu-darmstadt.de
}

\begin{abstract}
Virtual reality (VR) promises to allow for replicating the physical world. As consequence, it is used in the context of digital curating to enable remote exhibition visits. In this paper, we are exploring what visitors win and what they lose in virtual exhibitions compared to their original. We created a virtual representation of a physical exhibition those values highly depend on its authenticity by being located in an original historical place and showing only original artefact. In a user study, we compared the exhibition experience of the physical with the virtual exhibition and gathered ideas about how the pure virtual exhibition can be augmented using digital media. Afterwards, we conducted an interview with museum experts. We discussed the results and ideas proposed in the first experiment. In conclusion, we summarise potential application for augmented VR exhibitions and highlight their values and limitations.
\end{abstract}

Virtual Reality. Augmented virtuality. Virtual cultural heritage. Virtual museums.

\section{INTRODUCTION}

As virtual reality (VR) promises to allow for replicating the physical world, it is used in the context of digital curating to allow for virtual museum visits. While everybody with an Internet connection could theoretically visit virtual museums, only few people do. Interestingly, more and more people visit physical museums (Jung 2017). Consequently, one may suggest that virtual exhibitions are not fully understood and that more people will visit them if that changes. Therefore, the question that motivates this work is:

- What do we win and what do we lose in virtual exhibitions?

While VR has successfully entered the games market in the last few years through creating highly immersive experiences, virtual exhibitions do not provide similar user experience (UX).

Using digital media in museums and exhibitions is not new. There has been a long tradition in showing digital representations of cultural heritage artefacts in web-based archives, such as the museum-digital (http://www.museum-digital.de). Nowadays, VR technology allows for more authentic experiences through creating a 3D replica of a museum or $360^{\circ}$ views. Although such virtual museums do neither cost entry fee nor require travelling to their physical location, previous research has shown that simply replicating a physical space fails a good user experience (Styliani 2009). We hypothesis that a virtual museum can use mediated augmentation to increase user experience, which in turn could attract more visitors. To better understand how to increase UX in virtual museums, we aim to better understand the challenges of virtual exhibitions from the visitors' perspective, but we also want to learn from people that know museums best, their curators and employees, what kind of VR museum they would appreciate.

In a user study, we compared UX in a physical museum, the Otto Weidt Museum for the Blind, with the experience in its virtual replica. We gathered data about advantages of both, the physical and the virtual museum. Furthermore, we collected ideas about how media, content, and interactivity could be designed to beneficially augment the museum.

Afterwards, we presented these study results to the curators and employees of the physical museum. We interviewed these experts regarding their favours and doubts imagining a virtual replica of their museum presented to their visitors and to the world through the Internet. 


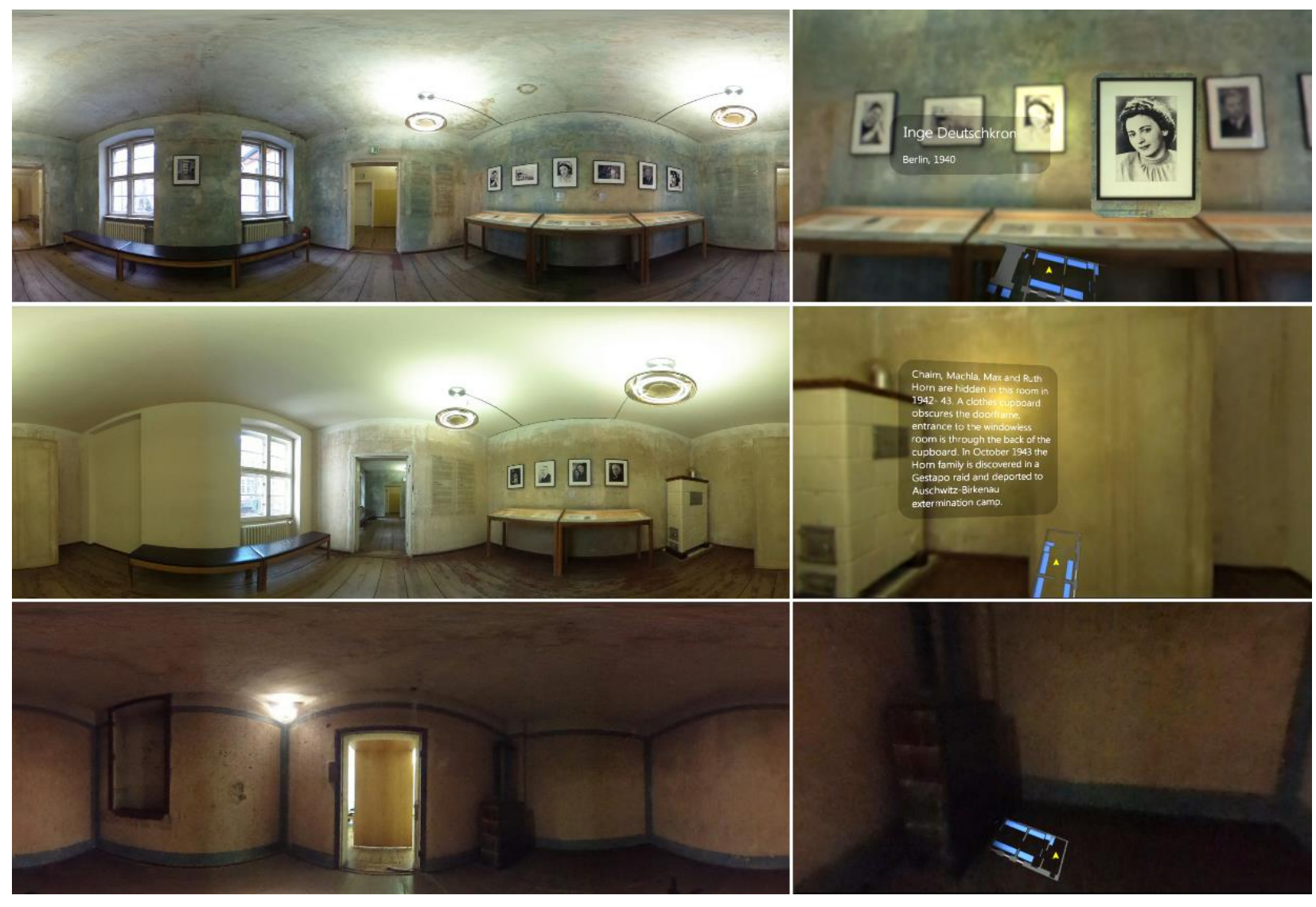

Figure 1: Left column: $360^{\circ}$ camera captures of the last three museum rooms, the last one is the hideout. Right column: VR views of the last three museum rooms with highlighted exhibits and corresponding labels.

\section{RELATED WORK}

Digital media in museums and exhibitions has been used for decades, and virtual museums, for example virtual replica of existing museums (Deggim 2017, Reinhardt 2018), are a slowly but constantly growing application domain (for example, see the list available online at: http://www.virtualfreesites.com/museums.museums .html). Moreover, Augmented Reality (AR) has been widely used to enrich UX in exhibitions since many years (Benko 2004, Hornecker 2010, Linaza 2007, Risseeuw 2016, Woods 2004).

Previous work mainly implemented VR systems to explore UX aspects. Neovesky and Peinelt (2015) published an open source generic software that allows its users to build virtual tours for all kinds of buildings and sites without any knowledge of programming. This software make it possible to create more advanced VR exhibitions than those generated with Google Open Gallery (https://www.google.com/opengallery), which still lacks in smooth navigation and is limited to only few interaction possibilities. Through analysing an immersive interactive virtual archaeology application for the broad public, Gaitatzes et al.
(2001) stated that while we are still at the early stages of using immersive VR for public access, such systems have great potential to enrich learning experiences. Farella et al. (2005) introduced a platform for interactive virtual heritage applications that integrates a VR system with wireless, connected portable and wearable computers for peer-to-peer information exchange. Ramic-Brkic et al. developed an augmented realtime virtual environment of the church of the holy trinity in Mostar (2009). Gomes et al. (2012) implemented a cave application; Ilha Musical is an interactive panoramic experience for children using a game competition and cooperation as a means of engaging children with each other. Gaitatzes et al. (2005) present a VR system informing about the Olympic Games in ancient Greece. The application uses interactivity to generate educational value through making the user/spectator be an interacting part of the edutainment activity. Park et al. (2006) developed Digital Koguryo, a virtual reality reconstruction of a Koguryo mural tumulus, designed to educate visitors in the cultural background and life style of the ancient Koguryo.

The authors of the related work agree that VR has great potential to enrich and expand museums, exhibitions and cultural heritage. With this paper, we intend to better understand how to realise that aim. 


\section{RESEARCH QUESTIONS}

It is widely accepted that virtual exhibitions result in a decrease in quality of UX compared to a visit in a real exhibition. We assume that this effect will particularly occur when originality and authenticity matter in a real exhibition, such as for original art works or authentic historical places.

Therefore, we selected as research context a museum that is highly authentic and full of original artefact and traces, as it is located at a historic original place. We chose the museum Otto Weidt's Workshop for the Blind in Berlin (http://www.museum-blindenwerkstatt.de). The museum used to be a brush workshop where blind and deaf people worked. During the era when the Nazi regime was in power, the owner of the workshop, Otto Weidt, employed Jewish people to protect them from the deportation to concentration camps. A cabinet occludes the entrance of the last room of the workshop, and a Jewish family was hidden there for nine months until the secret room was found during a Gestapo razzia. The family was then deported to Auschwitz and murdered. The Workshop for the Blind is located in the East of Berlin. During the socialistic area, it was closed in 1952 and afterwards partly used as storage rooms. Hence and gladly, the four last rooms of the workshop, including the secret hideout, were kept unchanged. The paint of the walls, the old creaking wooden floor, and some of the furnishing of the rooms have been conserved until the workshop rooms became a museum in 1999. That historic patina, the authentic atmosphere, and the dramatic events that took place in these rooms make a visit in the Workshop for the Blind a unique and an extremely emotional experience. Since a few years, visitors can have a look into the hideout room, but entering it is now forbidden to protect the original paint on the walls aiming to keep that place as authentic as possible.

Using VR would, of cause, allow visitors to enter the hideout as digital wall texture is neither authentic nor it can get damaged when touching it. While visitors could enter the hideout in a virtual Workshop for the Blind, we are sceptic if this would create an authentic experience. Hence, the Workshop for the Blind seems to be a museum where UX in VR is challenged and where the current fascination of VR technology may not compensate the loss of authenticity. Therefore, we believe that this museum is a perfect research context to answer research questions around UX limitations in VR. Hence, our first research question is:

- RQ1: How does virtuality change the user experience of an exhibition, in particular what gets lost and how does UX benefit?
For isolating the factor of virtuality, our approach was to compare the physical exhibition with an exact virtual replica showing the rooms of the Workshop for the Blind in Berlin and allowing for watching the same content as the one that is available in the exhibition. Aiming for fair conditions, we did not add content but also tried to not omit details that exist in the real exhibition. Hence, we created a pure virtual replica of the exhibition without any (content or interaction) augmentation.

As previous work suggested that pure virtual replicas of physical museums lack in UX, we see the replica as base to be able to understand limitations of VR but also as interaction probe that may trigger ideas about how to improve VR. Media augmentation or augmented virtuality (Milgram 1994 ) is a promising candidate to enhance UX. Hence, our second research question aim to gather idea for augmented virtual (AV) reality in the museum context.

- RQ2: What concepts for an augmented virtual Workshop for the Blind may be appropriate and would add value to the existing physical exhibition?

\section{USER STUDY}

We conducted a user study where visitors of the Workshop for the Blind experienced both, the real and a virtually created exhibition, aiming to get qualitative feedback on different UX aspects as well as ideas for $\mathrm{AV}$ exhibitions.

\subsection{Experiment design}

Our study had a within subject design with the independent variable exhibition type (real exhibition, virtual exhibition). The dependent variables were qualitative feedback on the exhibition types (RQ1) as well as ideas about media augmentation that may improve the UX of a virtual Workshop for the Blind (RQ2). We measured that feedback through a semi-structured postexperiment interview asking the following questions:

(i) What exhibition did you like more, the real or the virtual one and why?

(ii) What gets lost in the virtual exhibition compared with the real one?

(iii) What benefits has the virtual exhibition compared with the physical one?

(iv) What benefits could the virtual exhibition have if it would be available as free download in the Internet?

(v) Which additional possibilities/content you could image for the virtual exhibition? 
(vi) What additional interaction would enrich the virtual exhibition?

The answers were recorded using Google docs on a laptop that we provided.

\subsection{Participants}

We recruited 18 participants (7 females) aged from 18 to 77 (mean=29.7, SD=16.4) that were visiting the museum. Our participants came from 10 countries but mainly from Germany (Germany: 8, USA: 2, Canada: 1, GB: 1, Italy: 1, Hungary: 1, Serbia: 1, Spain: 1, Sweden: 1, Syria: 1). The participants were mainly tourists visiting Berlin. The time the participants spent was compensated with 10 EUR. The entry of the museum is always free for everybody.

\subsection{Apparatus}

For the real exhibition type, the physical Workshop for the Blind was used. For the condition of the virtual exhibition, we implemented an as authentic as possible virtual copy of the Workshop for the Blind in Unity3D. We captured the rooms with a $360^{\circ}$ camera (RICOH THETA S), as shown in Figure 1 on the images on the left column. Detailed information, like documents and photographs, were captured with higher resolution using an SLR camera, such as the photograph highlighted at the second column in the first row in Figure 1. Labels were recreated using Adobe Photoshop to allow for better readability than photographs, see at the images in the first and seconds rows of the second column in Figure 1. The participant's position in the virtual exhibition was visualised in a map through a yellow arrow that pointed into the direction the user was watching and/or moving. During that condition, participants wear Oculus Rift Dk2 while sitting on a chair in the seminar room of the museum.

The VR control worked as follow: As commonly used, head movements changed the VR perspective accordingly. We chose the touchpad on a laptop for additional gesture control as it can be eyes-freely found through the haptic feedback of its borders. Movements in VR could be realised through drag gestures on the touchpad of the laptop, which was placed on a table in front of the participants. The drag directions corresponded with the movement directions (left/right, up for forwards, down for backwards). If additional content was provided for an exhibit, it got a light shine as highlight when it appeared in the centre of the VR view. Selecting/showing the additional content was possible with a drag upwards using the touchpad. If content was selected, drag gestures to the right and left resulted in scrolling the content fore- and backwards. Deselecting the content, and thus being back in the movable state, could be realised through a drag gesture downwards. Pressing the space key allowed also for looking around when using the drag gestures at the same time. Without pressed space key, looking around (as mentioned above) was realised through head movements.

Our basic interaction design followed common conventions in VR control, such as view change through head movements. The motion and selection control using drag gesture was iteratively designed in our lab and evaluated in pilot studies with students.

\subsection{Procedure}

In the beginning of the user study, participants filled in a demographic questionnaire and signed a consent form. The experimental task was to explore the exhibition, once in VR and once in real. The condition order was counterbalanced. Before the exploration of the virtual exhibition, participants were equipped with the head mounted displays (HMD) and got a training to learn the interaction techniques. The VR condition took place in the seminar room of the museum, and also the postexperimental interview was done there. The experiment took place in the last three rooms of both, the real and the virtual exhibition to not let the study last too long.

During the condition of the real exhibition, participants were guided to the beginning of the third last room. They were told that they should visit the exhibition from there on till the end. We mentioned that participants could visit the rest of the exhibition after the experiment, so that they were not afraid to miss anything. We asked the participants to explore the exhibition as if they would not be part of an experiment, in their own speed and without a special memory task. We told them that we were interested in their personal exhibition experience.

After participant felt familiar with the commands for navigation, content selection and content navigation, the conditions of the virtual exhibition could start. Here, the application was started from the beginning of the third last room. We mentioned (like in the other condition) that participants should explore the virtual exhibition as if they would not be part of an experiment, in their own speed and without a special memory task. Again, we told them that we were interested in their personal virtual exhibition experience.

When both conditions were completed, participants answered the questions of the semi-structured interview. 


\section{RESULTS}

We analysed the interview answers using a bottomup analysis and open coding keeping the structure of our questions. Hereby, we found general trends that we describe in the following paragraphs, and we also highlight individual opinions when they are particularly relevant for our research questions:

(i) 12 out of 18 participants preferred the physical exhibition as it best represents the authenticity of the historical place, while another two equally liked both experiences.

(ii) Participants that favoured the real exhibition felt that its spatial atmosphere, the creaking sounds when walking across the old wooden floor, the originality of the documents, details of the room, such as the old texture of the walls, and the haptic experience of the workshop tools as well of the braille labels get lost. 8 participants missed the authentic mood in VR. One participant even missed the view out of the window where graffiti signs are visible on a wall, which represents the typical Berlin atmosphere of having historical places and street art next to each other. Moreover, one participant mentioned that in VR, "orientation in space is more difficult" and another participant similarly stated to "lose the sense of space" in VR.

(iii) Participants appreciated the option to select a language in VR as well as the opportunity to zoom into content. One participant highlighted that the real exhibition "allowed for closer approaching exhibits and enabled to better read texts" and another stated in the real exhibition "you can see more details of the place but on the VR it is easier to read the information". 6 participants highlighted that the information accessibility worked better in VR, as it was more visible, easier to read, no other people occluded the view, and one could longer and better concentrate on the content. In summary, even though the experience is suffering from a loss of atmosphere, the VR museum was still perceived to be authentic and to give a good virtual experience. Interestingly, the possibility to access the hideout in VR, which is impossible in reality, has not been mentioned.

(iv) Benefits of virtual exhibitions with webbased accessibility were highlighted, like a widespread access for people to visit such exhibitions from wherever there are and at any time. Moreover, suitable content access for impaired people was envisioned, e.g. using an auditory text augmentation of the documents or descriptions of photos. Finally, accessibility for less mobile people was highlighted, which would, for example, elderly people ease to visit the virtual museum.

(v) Participants could imagine having additional content in VR, such as "more languages", "more text", and "more things to learn" as well as video, auditory content and interactivity. One participant wished to have rotatable 3D models of the exhibits. One would like to have a virtual guide, and one proposed to include questions in the virtual exhibition application. For increasing the authenticity in VR, participants proposed to include sound effects of a factory or of the actual museum, smell, and the ability to physically walk in VR.

(vi) Participants wished to allow for even more zooming, to see much more detail. That would actually allow to extend the visibility of the original document through showing details that visitors barely can see with their eyes in the physical exhibition due to the limitation of the eye or due to the fact that documents are placed behind glass in showcases.

In summary, participants wish an increase of presence in the virtual exhibition and criticise that authentic atmosphere gets lost in VR. However, the ability to focus on content increases in VR. Content accessibility from everybody, everywhere, and at any time was highlighted to be the major advantage of $\mathrm{VR}$, and an augmentation with more content, interactive content and a better visibility of the content was proposed to enrich UX. Furthermore, a gamification approach was proposed, such as having a virtual guide and including questions.

\section{EXPERT INTERVIEWS}

As employees of museums decide whether a virtual museum will be developed and made accessible to the public, we decided to involve museum professionals into our research. As decision making in institutions is often a group process in which hierarchical relations matter, we aimed to conduct a group interview with the entire staff of the museum.

\subsection{Participants}

The Workshop for the Blind has only two employees, but it is affiliated with the organization Silent Heroes Memorial Center. For our interview, we recruited three women, the employee (museologist, 45 years old) of the Workshop for the 
Blind and an intern of the museum (academic high school graduate, 21 years old) as well as an employee of the Silent Heroes Memorial Center (historian, 57 years old).

\subsection{Procedure}

For the interview, we were welcomed in the office of the museum and presented the results of our user study to the professionals highlighting the recommendations how to augment museums in the future. Afterwards, we asked semi-structured questions about feedback on these ideas. In the end, we asked for opinions on general benefits and concerns regarding a virtually augmented Workshop for the Blind. The interview lasted approximately 90 minutes.

We present here feedback on AV application ideas for an augmented virtual Workshop for the Blind followed by feedback on the general value of VR/AV exhibitions.

\subsection{Interview Results}

\subsubsection{Gamification}

The experts liked gamification as they saw much potential to address young people. The museologist could image such application being used for introducing children to the exhibition topic before they would visit the real exhibition. The visit of the real exhibition was highlighted to be still important as it is at an authentic place. The intern liked the possibility to learn about the exhibition in a playful way, and also saw potential for using such playful learning approach after the exhibition visit, maybe even on a smartboard to involve the whole school class.

\subsubsection{Content augmentation}

Participants had wished to get additional content, such as sounds from workshops to create the feeling of authenticity and to get a time travel experience. While the idea of adding digital information to a virtual exhibition was in general appreciated, the experts mentioned that the museum has no archive and does not have any additional information that could be shown. The museum is small and shows already everything it has.

The museum professionals were explicitly sceptic about creating content based on suggestions how life would have looked like. Producing content, which is not original, would in their opinion create a wrong impression how the place used to be in the past. They found it a huge problem that they do not have original material, especially texts, that could be used. Creating content that tells history by guessing what people would have told was highly denied as that would be only speculation and errors would definitely occur in the stories. The museologist mentioned that Germans per se do not like staged story telling in historical contexts. In other counties people are more open, and the Empirical War Museum in UK is only one example. There, bombings are staged while visitors are in a bunker setting. The museologist said that no German museum would create such scene as the creation of artificial emotions related to topics like World War II would not be liked in Germany. The historian agreed that simulating the situation when the Gestapo found the Jews in the hideout would be inappropriate. The museum professionals questioned that such scene would be beneficial for anybody.

\subsubsection{General value of VR/AV exhibitions}

As general benefit of a virtual museum, the experts pointed out that a virtual museum could encourage people to visit the exhibition who are currently not addressable, such as young people and kids. These groups become very excited through VR and spend already a lot of their time in the Internet. The possibility to support more languages than in the real exhibition, where only German and English texts are provided, was desired. The option to add hyperlinks referring to external archives and to show more content, even though the Workshop for the Blind has none, was highlighted to be beneficial.

Even though the experts agreed that a virtual exhibition visit couldn't replace a real one, the museologist mentioned that the museum has difficulties to let all visitors in, as many people want to enter the museum whilst it is a small place. Offering a virtual replica of the exhibition would enable more people to see the exhibition.

In the end, the museum professionals discussed about the option of supporting VR for other museums. They agreed on the dependency of the kind of exhibits on the appropriateness to present them in VR. Museums that do not rely on authentic places and original artefacts as much as the Workshop for the Blind, may lose less when being virtualised. For example, replicas may also be viewed in VR. Moreover, some exhibitions, like the Jewish Museum Berlin, are too large to allow for seeing everything during one visit. Visitors could virtually "come back" and continue their visit at home. Finally, some exhibitions, like the Anne Frank exhibition in Amsterdam, are often too crowded to be enjoyable. One could go through the entire exhibition in VR without being distracted by other visitors, and nobody would occlude the view at exhibits. 


\section{CONCLUSION}

While VR technology enables the development of virtual museums and many VR exhibitions already exist, virtual exhibitions are not visited as often as theoretically possible via the web. Previous worked stated that there is still space of improvement for existing VR museums regarding their UX.

To better understand how to improve virtual museum experience, we conducted two experiments: first a VR/real museum comparison and second an expert interview with museum professionals.

Being in line with previous work, we found that pure VR indeed has benefits in comparison to real museums, as space, time, location, and money are no barriers of museum visits. We moreover confirm that authenticity and sensation of space get lost in VR. We identified media augmentation, interaction, and gamification to be promising concepts for augmenting virtual exhibitions, while the augmentation content has to fit the exhibition concept. In particular, we highlight context as limiting factor of $V R$ and $A V$ in museums. Some content may be not appropriate to be virtualised, e.g., original artefacts, and some content may not be appropriate to be augmented, e.g., information of sensitivity.

\section{ACKNOWLEDGEMENTS}

This work is supported by the German Ministry of Education and Research (BMBF) within the GEVAKUB project (01JKD1701B).

\section{REFERENCES}

Benko, H., Ishak, E. W., and Feiner, S. (2004) Collaborative Mixed Reality Visualization of an Archaeological Excavation. In Proceedings of the 3rd IEEE/ACM International Symposium on Mixed and Augmented Reality (ISMAR '04). IEEE Computer Society, Washington, DC, USA, pp.132140. DOI: $10.1109 /$ ISMAR.2004.23

Deggim, S., Kersten, T. P., Tschirschwitz, F., and Hinrichsen, N. (2017) Segeberg 1600 Reconstructing a Historic Town for Virtual Reality Visualisation as an Immersive Experience. International Archives of the Photogrammetry, Remote Sensing \& Spatial Information Sciences, 42.

Farella, E., Brunelli, D., Benini, L., Ricco, B., and Bonfigli, M. E. (2005) Pervasive Computing for Interactive Virtual Heritage. IEEE MultiMedia 12(3) (July 2005), pp.46-58. DOI:

10.1109/MMUL.2005.54
Gaitatzes, A., Christopoulos, D., and Papaioannou, G. (2005) Virtual Reality Systems and Applications: The Ancient Olympic Games. In: Proceedings of the 10th Panhellenic Conference on Advances in Informatics (PCl'05). Springer-Verlag, Berlin, Heidelberg, pp.155-165. DOI:

$10.1007 / 11573036 \quad 15$

Gaitatzes, A., Christopoulos, D., and Roussou, M. (2001) Reviving the Past: Cultural Heritage Meets Virtual Reality. In: Proceedings of the 2001 Conference on Virtual Reality, Archeology, and Cultural Heritage (VAST '01). ACM, New York, NY, USA, pp.103-110. DOI: 10.1145/584993.585011

Gomes, A., Oh, H., Chisik, Y., and Chen, M. (2012) Ilha Musical: A CAVE for Nurturing Cultural Appreciation. In: Proceedings of the 11th International Conference on Interaction Design and Children (IDC '12). ACM, New York, NY, USA, pp.232-235. DOI: $\underline{10.1145 / 2307096.2307133}$

Hornecker, E. (2010) Interactions Around a Contextually Embedded System. In Proceedings of the Fourth International Conference on Tangible, Embedded, and Embodied Interaction (TEI '10). ACM, New York, NY, USA, pp.169-176. DOI: 10.1145/1709886.1709916

Jung, Y., and Rowson Love, A. (2017) Systems Thinking in Museums: Theory and Practice. Rowman \& Littlefield.

Linaza, M. T., Cobos, Y., Mentxaka, J., Campos, M. K., and Penalba, M. (2007) Interactive Augmented Experiences for Cultural Historical Events. In: Proceedings of the 8th International Conference on Virtual Reality, Archaeology and Intelligent Cultural Heritage (VAST'07). Eurographics Association, Aire-la-Ville, Switzerland, pp.23-30. DOI: 10.2312/VAST/VAST07/023-030

Milgram. P., and Kishino, F. (1994) A Taxonomy of Mixed Reality Visual Displays. IEICE Transactions on Information and Systems 77(12) (1994), pp.1321-1329.

Neovesky, A., and Peinelt, J. (2015) A Virtual Tour to the Inscriptions of the UNESCO World Heritage Site St. Michael in Hildesheim. In: Proceedings of the Conference on Electronic Visualisation and the Arts. British Computer Society, pp.285-290.

Park, K. S., Cho, Y., and Park, S. (2006) Lessons Learned from Designing a Virtual Heritage Entertainment Application for Interactive Education. In: Proceedings of the 5th International Conference on Entertainment Computing (ICEC'06). SpringerVerlag, Berlin, Heidelberg, pp.233-238. DOI: $\underline{10.1007 / 1187232028}$

Ramic-Brkic, B., Karkin, Z., Sadzak, A., Selimovic, D., and Rizvic, S. (2009) Augmented Real-time Virtual Environment of the Church of the Holy Trinity in Mostar. In: Proceedings of the 10th 
International Conference on Virtual Reality, Archaeology and Cultural Heritage (VAST'09). Eurographics Association, Aire-la-Ville, Switzerland, pp.141-148. DOI:

10.2312/VAST/VAST09/141-148

Reinhardt, J., Rzayev, R., Henze, N., and Wolf, K. (2018) GhostVR: Enhancing Co-Presence in Social Virtual Environments. CHI'18 Workshop on Novel Interaction Techniques for Collaboration in VR.

Risseeuw, M., Cavada, D., Not, E., Zancanaro, M., Marshall, M. T., Petrelli, D., and Kubitza, T. (2016) Authoring Augmented Digital Experiences in Museums. In: Proceedings of the International Working Conference on Advanced Visual Interfaces (AVI '16). ACM, New York, NY, USA, pp.340-341. DOI:

10.1145/2909132.2926064

Styliani, S., Fotis, L., Kostas, K., and Petros, P. (2009). Virtual Museums, a Survey and Some Issues for Consideration. Journal of Cultural Heritage, 10(4), pp.520-528.

Woods, E., Billinghurst, M., Looser, J., Aldridge, G., Brown, D., Garrie, B., and Nelles, C. (2004) Augmenting the Science Centre and Museum Experience. In: Proceedings of the $2 \mathrm{Nd}$ International Conference on Computer Graphics and Interactive Techniques in Australasia and South East Asia (GRAPHITE '04). ACM, New York, NY, USA, pp.230-236. DOI: $\underline{10.1145 / 988834.988873}$ 